\title{
TENTATIVAS DE INCLUSÃO DA AGRICULTURA DE BASE ECOLÓGICA NO PRONAF: DO OTIMISMO DAS LINHAS DE CRÉDITO RURAL VERDE AO SONHO FRUSTRADO DO I PLANAPO ${ }^{1}$
}

\author{
ATTEMPTS TO INCLUSION OF ECOLOGICAL BASED AGRICULTURE IN \\ PRONAF: FROM THE OPTIMISM OF THE RURAL GREEN CREDIT LINES TO \\ THE FRUSTRATED DREAM OF THE I PLANAPO
}

\section{INTENTOS DE INCLUSIÓN DE LA AGRICULTURA DE BASE ECOLÓGICA EN EL PRONAF: DEL OPTIMISMO DE LAS LÍNEAS DE CRÉDITO VERDES RURALES AL SUEÑO FRUSTRADO DEL I PLANAPO}

\author{
Joacir Rufino de Aquino ${ }^{2}$ \\ https://orcid.org/0000-0003-0772-7141 \\ Marcio Gazolla ${ }^{3}$ \\ https://orcid.org/0000-0002-4807-6683 \\ Sergio Schneider ${ }^{4}$ \\ https://orcid.org/0000-0002-4353-6732
}

Submissão: 01/06/2020 / Aceito: 23/08/2020.

\section{RESUMO}

O objetivo deste artigo é analisar os principais avanços e limites das linhas de financiamento do Programa Nacional de Fortalecimento da Agricultura Familiar (PRONAF) criadas para apoiar a agricultura familiar de base ecológica no Brasil. Para tanto, recorre-se a uma revisão de parte selecionada da literatura produzida sobre o tema, bem como a sistematização de dados secundários sobre o desempenho das operações realizadas de 2004 a 2015, focalizando especialmente o período de abrangência do primeiro Plano Nacional de Agroecologia e Produção Orgânica (I PLANAPO). Em linhas gerais, o trabalho mostra que as chamadas "linhas de crédito verde" do PRONAF representaram uma inovação institucional importante, ocupando um lugar de destaque na agenda de prioridades do I PLANAPO, mas mantiveram uma posição marginal na política de crédito do programa, que continua apoiando majoritariamente a modernização da agricultura familiar e apresenta-se ainda muito distante das diretrizes de um sistema alimentar ambientalmente sustentável. Além disso, argumentase que os instrumentos inovadores que foram criados para financiar a agricultura familiar ecológica obtiveram um baixo desempenho operacional devido a problemas no seu desenho

\footnotetext{
${ }^{1} \mathrm{O}$ presente texto é uma versão resumida e atualizada de trabalho anterior publicado pelos autores (Cf. AQUINO; GAZOLLA; SCHNEIDER, 2017), o qual serviu de base para a elaboração de uma das questões da prova do $1^{\circ}$ dia do Exame Nacional do Ensino Médio (ENEM), em 2018.

${ }^{2}$ Mestre em Economia Rural e Regional (UFCG). Professor Adjunto IV do Curso de Economia da Universidade do Estado do Rio Grande do Norte (Campus de Assú). E-mail: joaciraquino@ yahoo.com.br.

${ }^{3}$ Doutor em Desenvolvimento Rural. Professor da Universidade Tecnológica Federal do Paraná (Campus de Pato Branco), vinculado ao Programa de Pós-Graduação em Desenvolvimento Regional (PPGDR). E-mail: marciogazolla1@gmail.com.

4 Doutor em Sociologia. Professor de Sociologia do Desenvolvimento Rural e Estudos Alimentares na Universidade Federal do Rio Grande do Sul, vinculado aos Programas de Pós-Graduação em Sociologia (PPGS) e Desenvolvimento Rural (PGDR). Bolsista PQ/CNPq. E-mail: schneide@ufrgs.br. DOI: http://dx.doi.org/10.22295/grifos.v30i51.5548 | Edição Vol. 30, Núm. 51, 2021
} 
normativo e a persistência de entraves relacionados à sua operacionalização em nível municipal, onde as políticas públicas pensadas em Brasília ganham vida a partir da ação concreta dos atores locais.

Palavras-chave: Agroecologia. Crédito Rural. Meio Ambiente. PLANAPO. PRONAF.

\begin{abstract}
The aim of this article is to analyze the main advances and limits of the financing lines of the National Program for Strengthening Family Farming (PRONAF) created to support ecologically based family farming in Brazil. For this, a review of selected part of the literature produced on the topic is used, as well as the systematization of secondary data on the performance of operations carried out from 2004 to 2015, focusing especially on the coverage period of the first National Plan for Agroecology and Organic Production (I PLANAPO). In general, the work shows that the so-called "green credit lines" of PRONAF represented an important institutional innovation, occupying a prominent place in the agenda of priorities of I PLANAPO, but maintained a marginal position in the program's credit policy, which continues to support mostly the modernization of family farming and is still a long way from the guidelines of an environmentally sustainable food system. In addition, it is argued that the innovative instruments that were created to finance ecological family farming obtained low operational performance due to problems in its normative design and the persistence of obstacles related to its operationalization at the municipal level, where public policies thought about Brasília come to life from the concrete action of local actors.
\end{abstract}

Keywords: Agroecology. Rural Credit. Environment. PLANAPO. PRONAF.

\title{
RESUMEN
}

El propósito de este artículo es analizar los principales avances y límites de las líneas de financiamiento del Programa Nacional de Fortalecimiento de la Agricultura Familiar (PRONAF) creado para apoyar la agricultura familiar de base ecológica en Brasil. Para ello, se utiliza una revisión de parte seleccionada de la literatura producida sobre el tema, así como la sistematización de datos secundarios sobre el desempeño de las operaciones realizadas entre 2004 y 2015, con especial atención al período de cobertura del primer Plan Nacional de Agroecología y Desarrollo. Producción Ecológica (I PLANAPO). En general, el trabajo muestra que las llamadas "líneas de crédito verdes" del PRONAF representaron una importante innovación institucional, ocupando un lugar destacado en la agenda de prioridades de I PLANAPO, pero mantuvieron una posición marginal en la política de crédito del programa, que continúa apoyando principalmente la modernización de la agricultura familiar y todavía está muy lejos de las pautas de un sistema alimentario ambientalmente sostenible. Además, se argumenta que los instrumentos innovadores que se crearon para financiar la agricultura familiar ecológica obtuvieron un bajo rendimiento operativo debido a problemas en su diseño normativo y la persistencia de obstáculos relacionados con su operacionalización a nivel municipal, donde las políticas públicas pensaban Brasilia cobra vida a partir de la acción concreta de los actores locales.

Palabras clave: Agroecología. Crédito Rural. Medio Ambiente. PLANAPO. PRONAF. 


\title{
INTRODUÇÃO
}

\begin{abstract}
O direcionamento de políticas para um público-alvo é, na verdade, uma tentativa - e não um resultado. Mesmo em casos nos quais bons resultados seriam absolutamente certos, isso não implica necessariamente que as tentativas na forma de programas de políticas direcionadas a um público-alvo produziriam esses resultados (SEN, 2000, p. 163, grifos nossos).
\end{abstract}

A agricultura de base ecológica e a produção orgânica de alimentos estão ganhando relevância em diferentes partes do mundo. No campo brasileiro, também acontece o mesmo. Impulsionado especialmente pela expansão da demanda de alimentos saudáveis, o setor cresce a cada ano, embora permaneça relativamente marginalizado na agenda de prioridades da política agrícola praticada no país.

Contudo, a partir da primeira década do século XXI, devido à pressão dos movimentos sociais e seguindo as recomendações de acordos internacionais, o governo brasileiro começou a apoiar a atividade em escala nacional, criando linhas de crédito e de financiamento rural subsidiadas, com foco principal na agricultura familiar, cuja expansão foi uma das metas principais do primeiro Plano Nacional de Agroecologia e Produção Orgânica (I PLANAPO), vigente de 2013-2015 (CIAPO, 2013; NIERDELE et al., 2019; SAMBUICHI et al., 2017).

O lançamento das modalidades de financiamento "verde", no âmbito do Programa Nacional de Fortalecimento da Agricultura Familiar (PRONAF), foi visto com otimismo. Teoricamente, elas ampliariam as possibilidades de investimento dos agricultores interessados em trilhar caminhos alternativos ao padrão tecnológico de modernização da agricultura pautado no uso intensivo de máquinas e insumos químicos, predominante no espaço rural desde os anos 1970. O problema é que isso não vem acontecendo conforme o planejado, pois as operações não conseguiram deslanchar apesar dos esforços dos atores governamentais e dos movimentos sociais do campo (AQUINO; SCHNEIDER, 2015; WEID, 2007).

Na busca de compreender a dinâmica desse processo, o objetivo deste artigo é analisar o desempenho das "linhas de crédito verde" da política de financiamento do PRONAF, desde as propostas iniciais adotadas no início dos anos 2000, até o desfecho do I PLANAPO, em 2015. Assim, a abordagem retrospectiva adotada se concentra em um momento singular na história brasileira no que se refere a proposição de políticas públicas para a agricultura familiar, o qual antecede as consequências da crise institucional iniciada em 2015/16 
(MATTEI, 2017; MATTOS, 2018; SABOURIN; CRAVIOTTI; MILHORANCE, 2020). Com isto, pretende-se demonstrar que mesmo antes da referida crise, quando ainda prevalecia um ambiente político favorável e estabilizado, a lógica operacional do PRONAF se mostrou resistente a mudanças, frustrando as "tentativas" (no sentido destacado na epígrafe acima) de incentivo à produção de alimentos agroecológicos e orgânicos.

Em termos metodológicos, a elaboração do estudo baseou-se na revisão de parte selecionada da literatura disponível sobre o tema. Também foram consultados dados secundários do Anuário Estatístico do Crédito Rural e da Matriz de Dados do Crédito Rural, do Banco Central do Brasil (BACEN). Outras informações relevantes foram obtidas na página do extinto Ministério do Desenvolvimento Agrário (MDA) e nos sites do Instituto de Pesquisa Econômica Aplicada (IPEA) e do Instituto Brasileiro de Geografia e Estatística (IBGE).

A estrutura do texto está dividida em três seções, além desta Introdução e das Considerações Finais. A segunda seção trata do viés produtivista que tem caracterizado o PRONAF e do otimismo verificado com a criação das linhas especiais de financiamento destinadas a incentivar a produção de base ecológica. Na terceira seção analisam-se o desempenho limitado das mencionadas linhas de financiamento e os principais obstáculos para a sua maior abrangência. Já a quarta seção detalha a proposta do I PLANAPO e, em seguida, apresenta um panorama das aplicações PRONAF Verde durante sua vigência de 2013 a 2015, a fim de verificar mudanças, continuidades e desafios.

\section{O VIÉS PRODUTIVISTA DO PRONAF E AS CARACTERÍSTICAS INOVADORAS DE SUAS LINHAS DE CRÉDITO RURAL VERDE}

A existência de uma política pública de crédito e financiamento rural estruturada é um requisito fundamental para viabilizar o desenvolvimento rural de uma nação. Desse modo, em muitos lugares do globo, os programas de crédito rural subsidiados são utilizados para estimular a produção agrícola e induzir mudanças sociotécnicas no campo. Para tanto, os recursos são ofertados aos agricultores, geralmente, a taxas de juros mais baixas do que as vigentes no mercado financeiro, além da exigência de garantias e de prazos de pagamentos diferenciados de acordo com as modalidades de empréstimos e os tipos de agricultores atendidos. 
Ao abordar o tema, Leite (2012) lembra que a política de crédito rural atua como sinalizadora dos setores ou culturas que um país pretende incentivar ou conter a expansão. Ao destinar um grande volume de recursos subsidiados para financiar um determinado tipo de lavoura ou matriz tecnológica, em detrimento de outras alternativas, o Estado indica claramente sua opção por um padrão ou estilo produtivo " $\mathrm{X}$ " ou "Y".

No caso do Brasil, a política de crédito rural foi institucionalizada na década de 1960, com o objetivo principal de promover a modernização tecnológica da agropecuária. Assim, em termos estratégicos, o estilo de desenvolvimento privilegiado procurou difundir a mecanização adaptada aos processos produtivos, pautada nas monoculturas e no uso intensivo de produtos químicos nas lavouras (DELGADO, 2012; GONÇALVES NETO, 1997; GRAZIANO DA SILVA, 1998; SAYAD, 1984).

Note-se que até mesmo o PRONAF, considerado a primeira e talvez a mais importante das políticas a favor da agricultura familiar em operação no país, tem seguido o caminho da modernização produtivista (CARNEIRO, 1997; CAPELLESSO; CAZELLA; ROVER, 2016; IBASE, 2006; FECAMP, 2002). De fato, é preciso reconhecer que o programa incluiu uma parcela importante dos agricultores familiares no mercado financeiro. Porém, não se pode esquecer que ele tem contribuído decisivamente para a disseminação do pacote tecnológico modernizante entre este tipo de produtor, especialmente após o lançamento do PRONAF Mais Alimentos em 2008, que fortaleceu a produção de commodities entre a parcela mais capitalizada da categoria situada nas regiões Sul e Sudeste (AQUINO; SCHNEIDER, 2015; TEIXEIRA, 2011, 2012; WEID, 2010).

A relação do PRONAF com as commodities e o seu viés produtivista modernizante podem ser melhor visualizados no Gráfico 1 . Observe-se que, em 2014, 32\% dos recursos de custeio do programa foram carreados para as monoculturas da soja, $24 \%$ para as lavouras de milho e $12 \%$ foram aplicados em outras commodities (fora soja e milho). Juntas, tais atividades somaram mais de dois terços dos recursos financiados (68\%). Enquanto isso, a produção dos demais alimentos básicos (feijão, arroz, frutas, legumes etc.) foi contemplada com apenas $17 \%$ do montante de recursos aplicados. 
Gráfico 1 - Distribuição do crédito de custeio do PRONAF segundo produtos e aplicações 2003 a $2014($ Em \%)

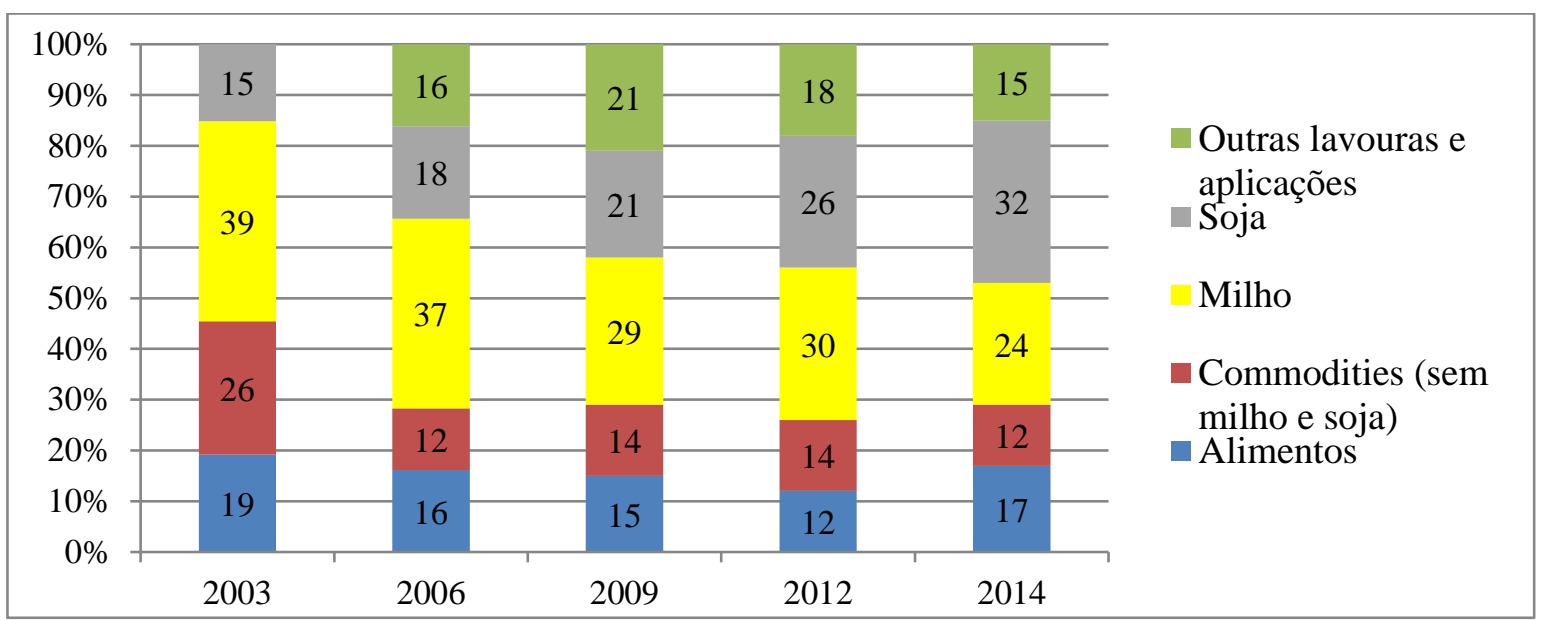

Fonte: Silveira et al. (2016, p. 26).

Os resultados produtivos do modelo agrícola estimulado pelos fundos públicos subsidiados pelo Estado são notáveis (BUAINAIN et al., 2013; GASQUES et al., 2010). No entanto, ao longo do tempo, o estilo de modernização incentivada pelo crédito rural no Brasil tem sido questionado pelo seu perfil concentrador e por seus impactos ambientais. Isso tem aberto espaço para algumas modificações na configuração do sistema, que começa a passar por um incipiente processo de "esverdeamento".

Nos anos 2000, quando os recursos subsidiados do crédito rural voltaram a crescer depois de um longo período de estagnação desde o início da década de 1980, registraram-se as primeiras tentativas de mudanças qualitativas nessa perspectiva. A partir de então, começaram a surgir novos arranjos institucionais, a exemplo das já denominadas "linhas de crédito verde", orientadas ao apoio de sistemas de produção de alimentos agroecológicos e orgânicos desenvolvidos pela agricultura familiar e, de forma bem mais tímida, pela agricultura empresarial via o Programa Agricultura de Baixo Carbono - $\mathrm{ABC}$ (OBSERVATÓRIO ABC, 2013; SAMBUICHI et al., 2012).

Quanto à agricultura familiar, as avaliações negativas da academia sobre o viés produtivista e modernizante do PRONAF e as pressões dos movimentos sociais fizeram o governo realizar modificações importantes nas formas de acesso aos recursos subsidiados do programa. Nesse sentido, foram criadas as linhas especiais de crédito de investimento PRONAF Agroecologia, PRONAF Floresta, PRONAF Semiárido e PRONAF ECO, 
doravante denominadas a partir da literatura de PRONAF Verde (OLIVEIRA et al., 2012; SAMBUICHI; OLIVEIRA, 2011; SAMBUICHI et al., 2012).

Weid (2006; 2007), entre outros, destacam que o lançamento desses novos instrumentos de financiamento, ao longo da primeira década do século XXI, representou o reconhecimento dos policy makers em relação às demandas emanadas das organizações da agricultura familiar pela construção de um modelo agrícola ambientalmente sustentável. Ademais, ampliou as oportunidades de investimento dos agricultores interessados em tornar seus sistemas produtivos mais harmoniosos com a natureza.

As linhas de crédito do PRONAF Verde começaram a operar em 2003, quase sete anos depois da criação do programa em 1996, tendo como público potencial os 4,4 milhões de estabelecimentos familiares existentes no Brasil, segundo o Censo Agropecuário 2006 (SEIBT, 2015). Conforme mostra o Quadro 1, essas modalidades especiais de financiamento têm em comum a orientação geral de buscar melhorar o uso dos recursos naturais no meio rural, estimulando a adoção de práticas conservacionistas e alternativas tecnológicas menos agressivas ao meio ambiente. Seu objetivo maior é criar condições para a aceleração do processo transição das agriculturas tradicional, convencional e/ou "moderna" para a sustentável, fortalecendo com apoio financeiro e assistência técnica vinculada aos empréstimos as iniciativas que vêm sendo realizadas no âmbito das unidades familiares de produção (GUADAGNIN, 2010; MDA, 2016).

Quadro 1 - Objetivos das linhas de crédito de investimento do PRONAF Verde

\begin{tabular}{|c|c|l|}
\hline LINHA DE CRÉDITO & $\begin{array}{c}\text { INÍCIO DA } \\
\text { OPERAÇÃO }\end{array}$ & \multicolumn{1}{|c|}{ OBJETIVO } \\
\hline PRONAF Floresta & $2003 / 2004$ & $\begin{array}{l}\text { Financiar a implantação e manutenção de sistemas agroflorestais, manejo } \\
\text { florestal e exploração extrativista ecologicamente sustentável, áreas de } \\
\text { preservação permanente, reserva legal, recuperação de áreas degradadas e } \\
\text { enriquecimento de áreas que já apresentam cobertura florestal } \\
\text { diversificada com espécies nativas. }\end{array}$ \\
\hline PRONAF Semiárido & $2003 / 2004$ & $\begin{array}{l}\text { Financiar investimentos em projetos de convivência com o semiárido, } \\
\text { focando na sustentabilidade dos agroecossistemas e priorizando projetos } \\
\text { de infraestrutura hídrica e implantação, ampliação, recuperação ou } \\
\text { modernização das demais infraestruturas. }\end{array}$ \\
\hline PRONAF Agroecologia & $\begin{array}{l}\text { Financiar a implantação e manutenção de sistemas agroecológicos de } \\
\text { produção, conforme normas estabelecidas pela Secretaria da Agricultura } \\
\text { Familiar do Ministério do Desenvolvimento Agrário (MDA), e sistemas } \\
\text { orgânicos de produção, conforme normas estabelecidas pelo Ministério da } \\
\text { Agricultura, Pecuária e Abastecimento (MAPA). }\end{array}$ \\
\hline PRONAF ECO & $\begin{array}{l}\text { Financiar a implantação, utilização e/ou recuperação de tecnologias para } \\
\text { produção de energia renovável, tecnologias ambientais, sistemas de } \\
\text { armazenamento hídrico, silvicultura e a adoção de práticas } \\
\text { conservacionistas e de correção da acidez e fertilidade do solo. }\end{array}$ \\
\hline
\end{tabular}

Fonte: Oliveira et al. (2012, p. 10-11).

DOI: http://dx.doi.org/10.22295/grifos.v30i51.5548 | Edição Vol. 30, Núm. 51, 2021. 
Analistas como Oliveira et al. (2012) e Weid (2006; 2007) consideram que as linhas de crédito que compõem o PRONAF Verde são inovações na política de crédito rural brasileira que buscam abrir novos caminhos para ações ambientalmente sustentáveis no âmbito da agricultura familiar. Na mesma direção, Moser e Gonzalez (2016) destacam que as modalidades de financiamento verde são inovadoras ao contribuir para mitigar as causas do aquecimento global e tornar os produtores familiares mais resilientes aos efeitos das mudanças climáticas. Capellesso, Cazella e Rover (2016), contudo, destacam que a inclusão do referencial da agricultura de base ecológica no PRONAF não implicou a superação imediata do seu viés tecnológico modernizante, mas a abertura de oportunidades para mudanças que poderiam se concretizar ou não.

A dinâmica operacional das modalidades de financiamento analisadas envolve uma sequência de etapas interligadas que vão da esfera federal até o nível municipal. Todo o processo começa em Brasília onde cada programa é desenhado e são definidas suas normas de funcionamento, como as finalidades do crédito, limites, prazos e taxas de juros mais baixas para estimular a participação dos agricultores e viabilizar os empreendimentos (BÚRIGO, 2010; PARENTE, 2004). Encerrada essa fase, as "regras do jogo" e os produtos financeiros eram divulgados nos extintos Planos Safra da Agricultura Familiar, tendo os bancos a autorização para contratar os empréstimos nos municípios.

Em nível municipal, como é demonstrado no Fluxograma 1, o primeiro passo é a divulgação das linhas de crédito pelos bancos e pelas entidades de classe que representam as categorias de agricultores. Uma parcela dos produtores, que recebe a informação por uma dessas fontes, decide acessar o crédito motivada por suas necessidades de capital de investimento e atraída pelos subsídios embutidos nas linhas especiais. Mas para isso, os demandantes necessitam contar com o apoio de um profissional de ATER (pública ou privada), que elabora um projeto técnico de uso do crédito onde detalha o investimento que será desenvolvido com os recursos subsidiados, bem como a previsão de receitas, despesas e rentabilidade que atestem a viabilidade econômica da atividade. 
Fluxograma 1 - Etapas do processo de operacionalização das linhas de crédito rural do PRONAF Verde em nível municipal

Divulgação das linhas de crédito verde pelos bancos e organizações de classe dos agricultores

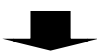

Mobilização dos produtores que acessam a informação e decidem fazer os empréstimos

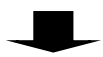

Elaboração do projeto de crédito verde por um profissional de assistência técnica e extensão rural (ATER) credenciado

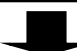

Envio do projeto e demais documentos exigidos aos agentes financeiros (bancos públicos)

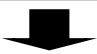

Análise do enquadramento e da viabilidade técnica do projeto pelos gerentes de crédito dos bancos públicos

Liberação do crédito e realização dos investimentos programados pelos produtores beneficiados

Fonte: Elaboração dos autores.

Note-se que, conforme a legislação vigente, os empreendimentos de agricultura de base ecológica financiados não poderão contemplar o uso de qualquer tipo de insumo químico (fertilizantes, agrotóxicos, etc.) ou organismos geneticamente modificados. Observada essa exigência, os projetos são encaminhados às agências dos bancos públicos (Banco do Brasil BB, Banco do Nordeste do Brasil - BNB, Banco da Amazônia - BASA, entre outros) para avaliação e possível liberação dos recursos de acordo com as regras estabelecidas nos normativos do Banco Central (BACEN).

Vale destacar que os sistemas de produção financiados por meio das linhas de crédito verde, além de ambientalmente sustentáveis, precisam ser economicamente viáveis, pois os empréstimos devem ser reembolsados nos prazos estabelecidos. Ademais, os bancos operadores decidem se concedem ou não os financiamentos considerando três fatores: o histórico do agricultor, a sua capacidade de endividamento e a viabilidade econômica do projeto. O sucesso das operações realizadas, porém, não depende apenas da elaboração e aprovação dos empréstimos. Para tanto, é necessário que o serviço de ATER tenha continuidade nas fases de implantação e execução das atividades financiadas (GUADAGNIN, 2010; MDA, 2016). 
O andamento adequado da concessão dos empréstimos apresentado depende, portanto, do desenvolvimento harmônico de todas as etapas descritas, desde a elaboração das normas e definição dos subsídios até a efetivação dos contratos em nível local.

O processo de liberação dos recursos também exige a interação entre o conjunto de atores envolvidos nas etapas mostradas no Fluxograma 1 (agricultores, organizações de classe, profissionais de ATER e agentes financeiros - bancos públicos e cooperativas de crédito), os quais formam a rede de relações sociais que garantem o ambiente institucional de funcionamento do PRONAF. Conforme lembram Abrahão (2007) e Godoi, Búrigo e Cazella (2016), a questão é que isso nem sempre acontece na prática. Como será discutido a seguir, há vários problemas no desenho e na operacionalização das ações planejadas, contribuindo para criar uma grande distância entre as metas de desempenho estabelecidas em Brasília e os resultados observados nos municípios que formam a geografia nacional, onde as políticas públicas efetivamente ganham vida.

\section{PRONAF VERDE: DESEMPENHO, LIMITES E ENSINAMENTOS DOS SEUS PRIMEIROS ANOS DE EXISTÊNCIA}

A política de crédito rural brasileira demonstrou um desempenho quantitativo excepcional no transcorrer do período compreendido entre 2002 e 2012. Nesse intervalo de tempo, de acordo com dados do Anuário Estatístico do Crédito Rural (BACEN, 2014), foram aplicados $\mathrm{R} \$ 840,3$ bilhões em operações de custeio e investimento agropecuários. O PRONAF também manteve sua trajetória de crescimento no mesmo período, realizando 17,8 milhões de contratações e aplicando mais de R 91,6 bilhões. As linhas de financiamento voltadas ao fortalecimento da produção agroecológica e orgânica de alimentos, por sua vez, registraram um comportamento bem diferente dos indicadores ora apresentados.

A Tabela 1 indica que o PRONAF Verde financiou, de 2004 a 2011, um total de R\$ 367,1 milhões em 62.464 contratos, variando entre um mínimo de $\mathrm{R} \$ 23,8$ milhões aplicados em 2004-2005 e um máximo de $\mathrm{R}$ \$ 73,4 milhões contratados na safra 2006-2007. Contrariando as expectativas, observa-se que, dentre as linhas analisadas, o PRONAF Agroecologia foi o que financiou o menor volume de total de recursos e o menor número de contratos, não chegando a alcançar mil operações nas primeiras seis safras de sua existência. A melhor performance foi obtida pelo PRONAF Semiárido, cujas contratações estão DOI: http://dx.doi.org/10.22295/grifos.v30i51.5548 | Edição Vol. 30, Núm. 51, 2021. 
concentradas na Região Nordeste, onde localizam-se algo em torno da metade dos estabelecimentos familiares do país.

Tabela 1 - Número de contratos firmados e valor aplicado nas linhas do PRONAF Verde no Brasil - 2004 a 2011

\begin{tabular}{c|c|c|c|c|c|c|c|c|c|c}
\hline \multirow{2}{*}{ ANO SAFRA } & \multicolumn{2}{|c|}{$\begin{array}{c}\text { PRONAF } \\
\text { Floresta }\end{array}$} & \multicolumn{2}{c|}{$\begin{array}{c}\text { PRONAF } \\
\text { Semiárido }\end{array}$} & \multicolumn{2}{c|}{$\begin{array}{c}\text { PRONAF } \\
\text { Agroecologia }\end{array}$} & \multicolumn{2}{c|}{$\begin{array}{c}\text { PRONAF } \\
\text { ECO }\end{array}$} & \multicolumn{2}{c}{$\begin{array}{c}\text { Total PRONAF } \\
\text { Verde }\end{array}$} \\
\cline { 2 - 11 } & C & VA & C & VA & C & VA & C & VA & C & VA \\
\hline $2004-2005$ & 1.758 & 8,4 & 3.059 & 15,4 & - & - & - & - & 4.817 & 23,8 \\
\hline $2005-2006$ & 3.339 & 15,5 & 10.141 & 47,9 & 59 & 0,6 & - & - & 13.539 & 64,0 \\
\hline $2006-2007$ & 5.356 & 25,3 & 10.300 & 45,6 & 260 & 2,5 & - & - & 15.916 & 73,4 \\
\hline $2007-2008$ & 2.248 & 12,7 & 7.773 & 37,6 & 191 & 2,0 & 204 & 2,7 & 10.416 & 54,9 \\
\hline $2008-2009$ & 1.307 & 7,3 & 4.105 & 24,4 & 393 & 5,1 & 1.386 & 18,6 & 7.191 & 55,4 \\
\hline $2009-2010$ & 919 & 5,9 & 2.742 & 17,5 & 76 & 1,3 & 1.436 & 19,0 & 5.173 & 43,6 \\
\hline $2010-2011$ & 1.491 & 13,9 & 3.677 & 30,0 & 2 & 0,03 & 242 & 8,0 & 5.412 & 52,0 \\
\hline Total & $\mathbf{1 6 . 4 1 8}$ & $\mathbf{8 9 , 0}$ & $\mathbf{4 1 . 7 9 7}$ & $\mathbf{2 1 8 , 4}$ & $\mathbf{9 8 1}$ & $\mathbf{1 1 , 5}$ & $\mathbf{3 . 2 6 8}$ & $\mathbf{4 8 , 3}$ & $\mathbf{6 2 . 4 6 4}$ & $\mathbf{3 6 7 , 1}$ \\
\hline
\end{tabular}

Fonte: Sambuichi et al. (2012, p. 30). Dados agrupados pelos autores.

Legenda: $* \mathbf{C}=$ Contratos; $\mathbf{V A}=$ Valores Aplicados ( $\mathrm{R} \$$ milhões $)$.

Os dados sistematizados na tabela em foco mostram que as linhas do PRONAF Verde apresentaram um desempenho financeiro insignificante em comparação aos indicadores do restante da política de crédito nacional, bem como em relação às demais modalidades de financiamento do PRONAF voltadas à modernização da agricultura familiar. Segundo Sambuichi et al. (2012, p. 30-31):

Os valores totais financiados pelo PRONAF Verde da safra 2004-2005 à safra 20102011 correspondem apenas a $0,7 \%$ dos recursos aplicados e $0,5 \%$ do número de contratos firmados pelo PRONAF Geral nesse mesmo período (considerando custeio e investimento, sem incluir as linhas especiais de crédito). O PRONAF Mais Alimentos, por exemplo, outra linha especial de crédito implantada a partir da safra 2008-2009 com o objetivo de estimular a produção de alguns alimentos para consumo interno, financiou em apenas três safras o montante de $\mathrm{R} \$ 6,8$ bilhões, enquanto o PRONAF Verde aplicou apenas o correspondente a 2,2\% desse valor no mesmo período.

Com efeito, percebe-se que as chamadas linhas de crédito verde abriram um espaço importante para o financiamento de práticas agroecológicas e da produção orgânica de alimentos. Porém, essa inovação introduzida na política de crédito rural brasileira não avançou como o esperado nos seus primeiros anos de operação. Mas se existiam as linhas especiais de crédito e, em algumas modalidades, nem todos os recursos disponibilizados anualmente eram aplicados, por que a quantidade de financiamentos voltados a apoiar a agricultura de base ecológica foi tão reduzida no período? 
Uma rápida revisão da literatura produzida sobre o tema na época evidencia que vários fatores podiam explicar o quadro retratado. Eles estavam associados, por um lado, a problemas na concepção e no desenho normativo das novas modalidades de crédito estudadas; e, por outro lado, a um conjunto de obstáculos operacionais nas diferentes etapas do processo de liberação dos recursos financeiros em nível municipal elencadas no Fluxograma 1.

Quanto aos problemas de concepção e desenho normativo dos financiamentos verdes, verificava-se que as condições de pagamento não eram adequadas e que as exigências técnicas de enquadramento dos projetos para sistemas produtivos de base ecológica eram excessivamente burocráticas, em comparação a maior simplicidade para a tomada de recursos das demais linhas de investimento do Sistema Nacional de Crédito Rural (SNCR), orientadas apenas por uma lista de produtos financiáveis.

Linhas como o PRONAF Mais Alimentos, por exemplo, praticavam no período juros semelhantes ou bastante próximos aos do crédito verde, mas com menos exigências técnicas e ambientais (tais como planos de manejo florestal, declaração de empresas certificadoras de produtos orgânicos, etc.), o que induzia os agricultores a optarem por essas modalidades tradicionais de financiamento em detrimento dos novos instrumentos de apoio a agroecologia e a produção orgânica (GODOI; BÚRIGO; CAZELLA, 2016; WEID, 2007, 2010).

Já entre os obstáculos operacionais identificados com maior frequência para explicar a baixa demanda e o desempenho insignificante do PRONAF Verde, Aquino, Gazolla e Schneider (2017) destacam: a falta de divulgação e de conhecimento dos agricultores sobre as linhas de crédito especiais, a falta de assistência técnica adequada para elaborar os projetos de base ecológica, os custos elevados do processo de certificação orgânica por auditoria exigidos e as dificuldades burocráticas de acesso ao crédito junto aos bancos.

Os entraves relacionados ao acesso crédito junto aos agentes financeiros, em particular, passavam pela formatação inadequada das planilhas de apresentação dos projetos (adaptadas para mensurar o desempenho de produtos específicos e não de sistemas produtivos), falta da definição de metas de aplicação, carência de pessoal, desconhecimento das linhas de crédito verde por parte dos funcionários e/ou sua resistência em financiar projetos agroambientais que não eram prioritários nas agências (ABRAHÃO, 2007; PARENTE, 2004; SAMBUICHI et al., 2012; STAUB; MELLO, 2012; WEID, 2006, 2007).

Diante dos problemas elencados, representantes de entidades ligadas à agricultura familiar buscaram sugerir mudanças e estratégias para tentar ampliar a quantidade de DOI: http://dx.doi.org/10.22295/grifos.v30i51.5548 | Edição Vol. 30, Núm. 51, 2021. 
agricultores atendidos pelo PRONAF Verde. Nesse sentido, uma medida reivindicada pelo movimento agroecológico era a redução da taxa de juros do programa para $1 \%$ ao ano. Além disso, defendia-se que o governo deveria garantir recursos "carimbados" para as linhas especiais de crédito, visando garantir um percentual mínimo de investimentos na agricultura sustentável (ABRAHÃO, 2007; SIDERSKY, 2007). Weid (2010), por seu turno, foi além dessas propostas, sugerindo que a introdução de um "prêmio de adimplência" para os empréstimos contratados, na forma de um rebate de 50\%, tornaria esses instrumentos mais atrativos e estimularia os processos de transição agroecológica.

A maioria das tentativas de implementar as medidas sugeridas e ampliar o financiamento da agricultura sustentável não lograram êxito. A partir da promulgação da Política Nacional de Agroecologia e Produção Orgânica (PNAPO) e, depois, do primeiro Plano Nacional de Agroecologia e Produção Orgânica (I PLANAPO), as expectativas se renovaram. O I PLANAPO, de certa forma, reconheceu alguns dos desafios apresentados acima e buscou enfrentá-los. Mas, como será visto na sequência, os resultados não foram tão animadores quanto se esperava, tendo em vista que o viés modernizante do PRONAF permaneceu e as "linhas de crédito verde" mantiveram o seu comportamento pouco expressivo e declinante em relação aos demais instrumentos da política agrícola nacional.

\section{O I PLANAPO E A FRUSTRAÇÃO DO SONHO DE “ESVERDEAR" O PRONAF}

O I PLANAPO foi instituído, em 2013, com o objetivo de promover ações indutoras visando ampliar e fortalecer a produção orgânica e de base agroecológica no Brasil, tendo como público prioritário os agricultores familiares e outros segmentos de empreendedores rurais ligados à agricultura empresarial. Uma das diretrizes do Plano foi a promoção de sistemas produtivos ambientalmente sustentáveis e menos dependentes de insumos externos às propriedades. Nesse sentido, sua estrutura dividiu-se em quatro eixos estratégicos: i) produção; ii) uso e conservação de recursos naturais; iii) conhecimento; e iv) comercialização e consumo. A partir desses quatros eixos foram delineadas 14 metas e 125 inciativas a serem implementadas no período de sua vigência, de 2013 a 2015 (CIAPO, 2013, 2016; NIERDELE et al., 2019; SAMBUICHI et al., 2017).

Entre os consensos presentes no I PLANAPO, estava o de que as práticas agroecológicas requeriam o apoio de políticas públicas estruturantes, tais como "serviços de DOI: http://dx.doi.org/10.22295/grifos.v30i51.5548 | Edição Vol. 30, Núm. 51, 2021. 
crédito rural diferenciado". Isto posto, no leque de "macrodesafios" estabelecidos pela referida política, destacou-se: “A ampliação da utilização de crédito e outras formas de financiamento e fomento para o custeio e implantação de infraestruturas produtivas e comerciais" (CIAPO, 2013, p. 16).

O enfoque prioritário dado à oferta de crédito rural tinha uma dupla motivação. De um lado, por seu papel indutor de mudanças sociotécnicas; e, de outro, por ser considerado um instrumento fundamental para aumentar a capacidade de investimento dos agricultores brasileiros em sistemas de produção orgânica e de base agroecológica (FRANÇA; MARQUES; DEL GROSSI, 2016; OLIVEIRA, 2016).

Com efeito, o I PLANAPO identificou as linhas de crédito do PRONAF Verde e outras existentes no Brasil como uma oportunidade para fortalecer a agroecologia e a produção orgânica no campo. No entanto, reconhecia que o número de contratos realizados por meio dessas modalidades especiais de financiamento era muito reduzido. No diagnóstico inicial do Plano, em consonância com o aludido na seção anterior, argumentava-se que os maiores limites para a expansão das modalidades de crédito verde estavam associados à baixa capacitação de técnicos e agricultores e aos entraves colocados pelo sistema financeiro, que ainda não havia absorvido as particularidades dos sistemas produtivos de base ecológica.

Nesse contexto, o I PLANAPO tentou equacionar os gargalos apresentados promovendo um conjunto de inciativas voltadas à realização de ajustes e adequações da operacionalização das linhas de crédito verde, capacitação de técnicos de ATER e agentes financeiros para melhorar a elaboração e avaliação dos projetos financiados e desenvolvimento de normas e instrumentos para facilitar o acesso de mulheres e jovens ao crédito subsidiado (os quais são os membros que mais influenciam na decisão familiar de deixar o campo). Outra estratégia importante do Plano foi disponibilizar para aplicação um volume substancial de crédito agrícola no período de 2013 a 2015. Por meio do PRONAF, atendendo a demanda do movimento agroecológico por recursos "carimbados", o MDA garantiu no triênio $\mathrm{R}$ \$ 2,5 bilhões para custeio e investimento na produção agroecológica e orgânica da agricultura familiar (CIAPO, 2013).

Um olhar panorâmico sobre as iniciativas do I PLANAPO evidencia, de certa forma, que o Estado brasileiro se mostrou "permeável" às demandas da sociedade civil, parte delas elencadas na coletânea organizada por Weid (2007). Ao eleger as linhas de crédito rural verde como uma das suas prioridades, o Plano aprofundou o esforço de tentar trazer a agricultura DOI: http://dx.doi.org/10.22295/grifos.v30i51.5548 | Edição Vol. 30, Núm. 51, 2021. 
de base ecológica para dentro do PRONAF, consubstanciando a incorporação da vertente ambiental na política de crédito.

No entanto, os resultados obtidos frustraram as expectativas mais otimistas. Segundo reconhece o relatório de avaliação da CIAPO (2016, p. 27): “A constatação, ao final do ciclo 2013-2015 do PLANAPO, é de que o número de contratos de financiamento para a produção orgânica e de base agroecológica e o montante de recursos respectivos são ainda tímidos”.

A persistência da timidez das operações das linhas de crédito verde é visível quando se analisam os dados do Banco Central (BACEN), para o referido triênio, expostos na Tabela 3. No âmbito do PRONAF Verde, de 2013 a 2015, os recursos efetivamente aplicados somaram R\$ 131 milhões, distribuídos em 20.855 contratos de crédito, o que representa 5,24\% dos R \$ 2,5 bilhões disponibilizados inicialmente pelo I PLANAPO.

Note-se que nesse mesmo período o PRONAF realizou 5,5 milhões de operações no valor de R \$ 66,5 bilhões, denotando a manutenção do caráter residual das linhas especiais de apoio à agroecologia e a produção orgânica no conjunto de ações desenvolvidas pelo programa. Em comparação ao PRONAF Mais Alimentos, por exemplo, que aplicou um montante de $\mathrm{R} \$ 4,3$ bilhões durante a vigência do Plano, a participação do financiamento verde foi de apenas $3,04 \%$.

Individualmente, a linha de crédito verde que apresentou o pior desempenho foi o PRONAF Agroecologia, com 61 contratos efetivados e R 2,6 milhões aplicados. Os PRONAFs Floresta e ECO vêm em seguida, demonstrando um desempenho modesto em termos de contratos e valores aplicados. De todas as linhas estudadas, seguindo uma tendência já apresentada no período de 2004 a 2011 (Cf. Tabela 1), a que demonstrou o maior número de contratações foi o PRONAF Semiárido, tendo sido responsável por mais de 18 mil operações e por um volume aplicado de R \$ 86,5 milhões. Sem a contabilização dessa linha, como se observa na Tabela 3, a participação das inovações de cunho ambiental na política de crédito rural para a agricultura familiar se tornariam praticamente imperceptíveis. 
Tabela 3 - Número de contratos e valores aplicados pelas diferentes linhas de crédito do PRONAF no Brasil - 2013 a 2015

\begin{tabular}{l|c|c}
\hline \multicolumn{1}{c|}{ LINHAS DE CRÉDITO } & $\mathbf{N}^{\mathbf{0}}$ DE CONTRATOS & VALORES APLICADOS (R\$) \\
\hline Agroecologia (1) & $\mathbf{6 1}$ & $\mathbf{2 . 6 3 6 . 8 1 9 , 8 7}$ \\
\hline Agroindústria (custeio) & 205 & $499.621 .553,43$ \\
\hline Agroindústria (investimento) & 293 & $122.873 .743,99$ \\
\hline Custeio & 368.346 & $6.901 .757 .209,55$ \\
\hline ECO (2) & $\mathbf{9 9 2}$ & $\mathbf{1 4 . 7 4 9 . 5 9 5 , 7 2}$ \\
\hline Floresta (3) & $\mathbf{1 . 5 3 0}$ & $\mathbf{2 7 . 0 9 6 . 6 0 7 , 5 2}$ \\
\hline Jovem & 163 & $1.110 .107,24$ \\
\hline Mais Alimentos & 150.933 & $8.304 .035 .403,13$ \\
\hline Microcrédito & 380.675 & $24.080 .267,70$ \\
\hline Mulher & 1.879 & $7.415 .906,60$ \\
\hline Produtivo Orientado & 2.176 & $128.890 .657,62$ \\
\hline Reforma Agrária & 18.717 & $25.192 .369,56$ \\
\hline Reforma Agrária (microcrédito) & 2.741 & $\mathbf{5 3 . 4 3 1 . 3 3 8 . 9 6 5 , 3 1}$ \\
\hline Sem Subprograma & 4.588 .357 & $\mathbf{8 6 . 5 2 3 . 8 5 9 , 1 3}$ \\
\hline Semiárido (4) & $\mathbf{1 8 . 2 7 2}$ & $\mathbf{1 3 1 . 0 0 6 . 8 8 2 , 2 4}$ \\
\hline PRONAF Verde (1+2+3+4) & $\mathbf{2 0 . 8 5 5}$ & $\mathbf{6 6 . 4 6 4 . 3 5 6 . 3 0 0 , 5 1}$ \\
\hline PRONAF TOTAL & $\mathbf{5 . 5 3 5 . 3 4 0}$ & \\
\hline
\end{tabular}

Fonte: BACEN (2016). Dados organizados pelos autores.

O baixo desempenho do PRONAF Verde, porém, não pode ser encarado como um problema homogêneo. A geografia dos desembolsos das linhas do Programa revela desequilíbrios e especificidades regionais marcantes (Tabela 4). Os contratos do PRONAF Agroecologia se concentram na Região Sul, com 52,46\% do total, seguida da Região Nordeste, com 36,07\% e da Região Sudeste, com 11,48\% dos contratos nacionais. Não houve acesso a esta linha de crédito nas demais regiões. O PRONAF Floresta e o Semiárido apresentaram uma forte concentração nas Regiões Norte, Nordeste e Sudeste, respectivamente. Já os contratos do PRONAF ECO estavam concentrados, pela ordem, no Nordeste, Sul, Sudeste, Norte e no Centro-Oeste, que é a região do país onde as linhas de crédito verde eram praticamente ausentes.

Tabela 4 - Distribuição geográfica dos contratos do PRONAF Verde no Brasil - 2013 a

2015

\begin{tabular}{c|c|c|c|c|c|c|c|c}
\hline \multirow{2}{*}{ REGIÃO } & \multicolumn{2}{|c|}{ FLORESTA } & \multicolumn{2}{c|}{ SEMIÁRIDO } & AGROECOLOGIA & \multicolumn{2}{c}{ ECO } \\
\cline { 2 - 9 } & Número & $\mathbf{\%}$ & Número & $\mathbf{\%}$ & Número & \% & Número & \% \\
\hline Norte & 1.262 & 82,48 & 0 & 0,00 & 0 & 0,00 & 18 & 1,81 \\
\hline Nordeste & 87 & 5,69 & 14.055 & 76,92 & 22 & 36,07 & 630 & 63,51 \\
\hline Sudeste & 141 & 9,22 & 4.217 & 23,08 & 7 & 11,48 & 128 & 12,90 \\
\hline Sul & 40 & 2,61 & 0 & 0,00 & 32 & 52,46 & 213 & 21,47 \\
\hline Centro-Oeste & 0 & 0,00 & 0 & 0,00 & 0 & 0,00 & 3 & 0,30 \\
\hline Brasil & $\mathbf{1 . 5 3 0}$ & $\mathbf{1 0 0 , 0 0}$ & $\mathbf{1 8 . 2 7 2}$ & $\mathbf{1 0 0 , 0 0}$ & $\mathbf{6 1}$ & $\mathbf{1 0 0 , 0 0}$ & $\mathbf{9 9 2}$ & $\mathbf{1 0 0 , 0 0}$ \\
\hline \multicolumn{3}{c}{ Fonte: BACEN (2016). Dados organizados pelos autores. }
\end{tabular}


Outra questão que merece ser considerada era a proposta do I PLANAPO de ampliar a inserção das mulheres na política de crédito rural do PRONAF Verde. Esta ideia, porém, apresentou pouca efetividade. Para ilustrar, a Tabela 5 indica que a linha de crédito com menor ocorrência de mulheres foi a de Agroecologia. Isso porque, de 2013 a 2015, dos 61 projetos efetivados por essa modalidade financiamento, apenas 5 contratos $(8,20 \%)$ foram feitos por agricultoras familiares. Nas demais linhas, os resultados foram melhores, oscilando de 21 a 25\% das operações, mas muito abaixo das reinvindicações dos movimentos sociais, demonstrando o viés de gênero masculino prevalecente no PRONAF destacado por Silva et al. (2016).

Tabela 5 - Distribuição dos contratos do PRONAF Verde no Brasil por gênero - 2013 a 2015

\begin{tabular}{c|c|c|c|c|c|c|c|c}
\hline \multirow{2}{*}{ GÊNERO } & \multicolumn{2}{|c|}{ FLORESTA } & \multicolumn{2}{c|}{ SEMIÁRIDO } & \multicolumn{2}{c|}{ AGROECOLOGIA } & \multicolumn{2}{c}{ ECO } \\
\cline { 2 - 9 } & Número & $\boldsymbol{\%}$ & Número & $\boldsymbol{\%}$ & Número & $\boldsymbol{\%}$ & $\begin{array}{c}\text { Númer } \\
\mathbf{0}\end{array}$ & $\%$ \\
\hline Masculino & 1.143 & 74,71 & 14.406 & 78,84 & 56 & 91,80 & 743 & 74,90 \\
\hline Feminino & 387 & 25,29 & 3.866 & 21,16 & 5 & 8,20 & 249 & 25,10 \\
\hline TOTAL & $\mathbf{1 . 5 3 0}$ & $\mathbf{1 0 0 , 0 0}$ & $\mathbf{1 8 . 2 7 2}$ & $\mathbf{1 0 0 , 0 0}$ & $\mathbf{6 1}$ & $\mathbf{1 0 0 , 0 0}$ & $\mathbf{9 9 2}$ & $\mathbf{1 0 0 , 0 0}$ \\
\hline
\end{tabular}

Fonte: BACEN (2016). Dados organizados pelos autores.

Em síntese, o I PLANAPO inovou ao estabelecer iniciativas concretas visando amenizar as contradições socioambientais do PRONAF e fortalecer as bases de um padrão de agricultura de base ecológica. A construção deste Plano é em si um feito que deve ser celebrado, uma vez que são muito poucos os países que alcançaram este repto mesmo entre as nações desenvolvidas, com exceção da Dinamarca e de alguns outros (MAFF, 2015; STEIN, 2015). Assim, não se deve desmerecer a relevância das inovações apresentadas, embora sem esquecer que o Estado brasileiro somente foi levado nesta direção por conta da pressão dos atores sociais, que a muito tempo clamavam pela construção de políticas de financiamento favoráveis à produção agrícola sustentável. Todavia, em termos práticos, essa inovação se mostrou pouco efetiva.

Para ilustrar a afirmação do parágrafo anterior, basta dizer que a política de crédito rural brasileira, de 2013 a 2015, realizou 7,7 milhões de contratações e aplicou R \$ 458,4 bilhões (BACEN, 2016). Cotejando esses números com os indicadores inexpressivos das linhas de crédito verde, depreende-se que os fundos públicos continuam sendo direcionados predominantemente para fomentar o modelo agrícola produtivista, assentado em DOI: http://dx.doi.org/10.22295/grifos.v30i51.5548 | Edição Vol. 30, Núm. 51, 2021. 
monoculturas e no uso intensivo de máquinas e insumos químicos. Ao manter sua trajetória histórica praticamente inalterada, "a política pública de crédito se pauta principalmente nas ações em que os subsídios oficiais são empregados para reforçar uma lógica capitalista calcada em sistemas produtivos convencionais" (GODOI; BÚRIGO; CAZELLA, 2016, p. $653)$.

Desse modo, como reconheceu o próprio governo em documento elaborado para avaliar a execução das metas do I PLANAPO: "Em que pese os esforços das instituições para aprimorar as normas aplicáveis aos instrumentos de crédito, bem como capacitar técnicos e lideranças dos agricultores e agricultoras, a ampliação do acesso ao crédito para a produção orgânica e agroecológica permanece como um desafio para os próximos anos" (CIAPO, 2016, p. 30).

Não é possível identificar com precisão as causas do baixo desempenho orçamentário das linhas de crédito verde durante a vigência do I PLANAPO. Até o momento falta uma avaliação mais abrangente sobre o assunto, bem como sobre os resultados socioeconômicos dos investimentos realizados. Tudo indica, contudo, que o quadro apresentado estava associado à persistência dos problemas de concepção e de operacionalização dessas modalidades financiamento, tal qual foi mencionado sumariamente na seção anterior. Isso significa que os obstáculos não foram superados e há contramovimentos, uma vez que a introdução dos princípios da agroecologia no SNCR, como referencial de ação, revelou-se um processo incipiente e de difícil efetivação.

No que diz respeito às condições de pagamento, as linhas do PRONAF Verde permaneciam pouco atrativas para os agricultores. O relatório da CIAPO (2016) destacou que o MDA, em conjunto com o Ministério da Fazenda (MF), fez ajustes no PRONAF Verde em relação ao diferencial positivo dessa linha de financiamento, em termos de bônus de adimplência, juros, etc. Mas essa medida não aconteceu na prática porque não foi incorporado nenhum tipo de "rebate" às citadas modalidades de financiamento. Além disso, os juros do PRONAF Verde se elevaram durante a vigência do I PLANAPO, saltando de um patamar que variava de 1 a 2\% anuais na safra 2013/2014 para 2,5\% ao ano na safra 2015/2016.

Mediante tais condições de pagamento dificilmente os agricultores seriam estimulados a mudar suas escolhas tecnológicas. Isso se tornava mais grave, principalmente, quando se observava a persistente falta de divulgação das linhas de crédito estudadas. No campo de atuação do extinto MDA, por exemplo, a linha de financiamento mais difundida era o DOI: http://dx.doi.org/10.22295/grifos.v30i51.5548 | Edição Vol. 30, Núm. 51, 2021. 
PRONAF Mais Alimentos, conforme sugeria a abundante propaganda de diferentes tipos de tratores exposta no Anuário Brasileiro da Agricultura Familiar 2015 (SEIBT et al., 2015). Segundo França, Del Grossi e Marques (2016), essa seria uma medida acertada, haja vista que a modernização da agricultura familiar contribuiria para que o segmento cumprisse um duplo papel: produzir alimentos e estimular a indústria de máquinas e implementos agrícolas, algo estratégico no contexto da crise econômica que atingia o país.

Por seu turno, o gargalo da ATER continuava sendo o "calcanhar de Aquiles" da política de desenvolvimento rural brasileira. O relatório da CIAPO (2016) mostra que foram realizados alguns cursos de capacitação e chamadas de ATER previstos no I PLANAPO. Mas o fato é que a carência de assistência técnica especializada ainda se constitui em um dos principais gargalos para o baixo desempenho das linhas de crédito verde. Na maioria dos municípios brasileiros faltam profissionais de ATER capacitados para trabalhar com a agroecologia e esse tipo de tecnologia não é prioridade dos órgãos públicos que atuam no setor rural.

Por outro lado, as chamadas de ATER por contrato são insuficientes e descontínuas no tempo e no espaço. Logo, sem reestruturar o sistema de ATER pública, gratuita e de qualidade, em parceria com os estados e as prefeituras, dificilmente será constituído o “exército de multiplicadores" exigidos para ampliar o financiamento público da agroecologia e da produção orgânica de alimentos entre os agricultores das diferentes regiões que compõem o território nacional (OBSERVATÓRIO ABC, 2015; SIDERSKY, 2007).

É importante destacar ainda, nesse aspecto em particular, que os limites da ATER no Brasil não se resumem apenas a quantidade. Outro obstáculo que emperrou a expansão das linhas de crédito verde refere-se à formação profissional dos técnicos de ATER, especialmente os agrônomos. Educados a partir de uma concepção pedagógica tecnicista, segundo grades curriculares, muitas vezes, ancoradas nos princípios da agricultura convencional, a maior parte dos profissionais de agronomia em atividade no país não detêm os conhecimentos necessários para orientar os agricultores interessados em investir na agricultura de base ecológica (AHRENS et al., 2009; DIAS, 2008; MOURA, 2006). Sendo assim, em consonância com o aprendizado adquirido nos "bancos da faculdade", o foco de sua ação volta-se para os aspectos relacionados ao aumento da produção e da produtividade agrícolas por meio da difusão das chamadas "técnicas modernas" no campo (sementes 
transgênicas, agroquímicos), caminhando na contramão das propostas de construção de um estilo de agricultura sustentável.

Além dessas questões, registraram-se inúmeros problemas na operacionalização das linhas de crédito verde que não foram resolvidos pelas inciativas do I PLANAPO. Estudo realizado na Região Sul, sobre a modalidade do PRONAF Agroecologia, evidenciou que entre as dificuldades que os agricultores familiares ecologistas encontram para acessar o crédito rural estavam à burocracia ainda existente nas instituições financeiras, o longo tempo entre o encaminhamento do projeto técnico-econômico do crédito rural elaborado e sua efetiva liberação (o que desestimula os investimentos familiares). Ademais, uma das principais questões apontadas é a de que as instituições financeiras não compreendem o que significa agroecologia ou mesmo produção orgânica, direcionando os financiamentos para outras modalidades modernizantes do PRONAF, como o crédito de investimento na linha Mais Alimentos (KLUCK; GAZOLLA, 2014).

Na mesma direção, a pesquisa de Godoi, Búrigo e Cazella (2016) revelou que a incorporação do referencial da sustentabilidade ambiental no PRONAF ainda não havia gerado mudanças operacionais significativas no âmbito das organizações financeiras locais. A incorporação do tema no atendimento aos beneficiários do programa ocorria mais pelo posicionamento sociopolítico da organização e menos pela indução gerada por mudanças normativas e/ou pela incorporação de novas linhas de crédito com caráter sustentável. Conforme os autores, "mesmo quando tenta introduzir a sustentabilidade em suas diretrizes e normativas, essa inovação esbarra na visão de mundo e na conduta gerencial tradicional dos agentes financeiros e demais operadores" (GODOI; BÚRIGO; CAZELLA, 2016, p. 659).

Cada um dos aspectos mencionados deve ser levado em conta. Contudo, eles são insuficientes para explicar o fenômeno estudado se não for considerado a grande contradição da forma de atuação do governo brasileiro no período. Essa contradição se materializou nos contrassensos entre as metas do I PLANAPO e dos Planos Safra da Agricultura Familiar, que em nenhum momento colocaram as linhas de financiamento verde como prioridade e, já no II PLANAPO (2016-2019), não foi mais destinado nenhum montante específico de recursos “carimbados" para a agricultura de base ecológica.

Sendo assim, o quadro apresentado também apresenta uma explicação de natureza histórica. Nunca é demais lembrar que a política de crédito rural brasileira está fortemente arraigada aos pilares técnico-produtivos modernizantes que marcaram a sua criação, DOI: http://dx.doi.org/10.22295/grifos.v30i51.5548 | Edição Vol. 30, Núm. 51, 2021. 
configurando um contexto que os economistas institucionalistas como North (1990) identificaram como “dependência de trajetória”. Seguindo essa corrente teórica, pode-se dizer que foi realizada uma alteração inovativa na nomenclatura dos instrumentos do PRONAF, mas não ocorreu uma mudança nas instituições (ou nas "regras do jogo") que modelam os comportamentos dos atores envolvidos no processo de desenvolvimento rural, contribuindo para se continuar "fazendo mais do mesmo". Tal cenário se agravou nos anos seguintes por conta da descontinuidade e desmonte das políticas públicas de desenvolvimento rural com a crise institucional instaurada em 2015/16, que aprofundou ainda mais a marginalização da agricultura de base ecológica na agenda de prioridades do governo brasileiro.

Como resultado, assiste-se no país a persistência de um baixo número de agricultores que praticam agricultura ecológica. Isso porque, conforme os dados do Censo Agropecuário 2017 (IBGE, 2019), do universo de 3.897.408 agricultores familiares existentes no Brasil, apenas $49.330(1,26 \%)$ declararam que desenvolviam a agricultura orgânica, demonstrando que depois do encerramento do I PLANAPO não foram registrados avanços na situação analisada aqui. Assim sendo, verifica-se a necessidade urgente de realizar novos esforços para estimular os processos de transição ecológica da agricultura familiar nacional e expandir a criação de novas unidades produtivas sustentáveis no campo. Isso pode fortalecer a preservação do meio ambiente e contribuir para ampliar a oferta de alimentos sustentáveis e saudáveis, beneficiando os produtores e os consumidores das cidades.

\section{CONSIDERAÇÕES FINAIS}

O Sistema Nacional de Crédito Rural (SNCR) historicamente tem ajudado a modernizar a agricultura no Brasil, principalmente dando suporte aos médios e grandes produtores, financiando cultivos voltados aos mercados externos e com uso em larga escala de insumos químicos e agrotóxicos. Esse quadro começou a se alterar a partir da metade dos anos 1990, quando o Estado passou a reconhecer e a incorporar os agricultores familiares, mediante a criação do PRONAF. No entanto, a política de crédito rural nacional não havia resolvido um dos seus principais pontos críticos referente a sua fragilidade e resignação em relação aos aspectos socioambientais. Com a criação das modalidades de financiamento verde do PRONAF, parecia existir uma perspectiva otimista de mudança no horizonte, mesmo sem a ruptura imediata do viés produtivista incorporado ao programa.

$$
\text { DOI: http://dx.doi.org/10.22295/grifos.v30i51.5548 | Edição Vol. 30, Núm. 51, } 2021 .
$$


Contudo, este indicativo de "esverdeamento" da política de crédito rural direcionada à agricultura familiar representou apenas uma inovação parcial e incremental. Como os dados analisados evidenciaram, as modalidades de financiamento da agricultura de base ecológica apresentaram baixo número de contratos, reduzidos valores aplicados e se defrontaram com condições de operacionalização pouco estimulantes e muito parecidas com as demais modalidades de empréstimos voltadas à modernização das lavouras (por exemplo, no que se refere as taxas de juros praticadas).

Isto significa que as mudanças institucionais necessárias são difíceis de serem operadas, tanto do ponto de vista da burocracia estatal, como dos diversos atores envolvidos na arquitetura da política de crédito rural (agricultores, extensionistas, agentes financeiros, organizações de representação política dos agricultores, entre outros). Em função desses obstáculos, os avanços no financiamento da produção sustentável entre os agricultores familiares brasileiros ainda são pífios e quase irrelevantes em números e resultados.

Além desta situação de inércia institucional em relação às mudanças na política de crédito rural para ativar o processo de "esverdeamento", há outros elementos que contribuíram para o parco avanço nas linhas de financiamento da produção ecológica de alimentos. A falta de tradição dos agentes em operar com este tipo de crédito rural e o pouco entendimento das instituições financeiras sobre as especificidades $\mathrm{e}$ as vantagens sociotécnicas da agricultura de base ecológica, tem feito as mesmas burocratizarem a tomada dos empréstimos ou não incentivarem a sua ampliação.

Corrobora com isso a falta de divulgação e de conhecimento dos agricultores sobre as linhas de crédito rural diferenciadas, a carência de assistência técnica especializada para elaborar os projetos técnicos de base ecológica, os problemas de operacionalização em nível local e os custos elevados do processo de certificação auditada que os alimentos orgânicos requerem para acessar determinados tipos de mercados. Também explica o baixo número de contratos e recursos acessados do PRONAF Verde, o pequeno contingente de produtores familiares ecológicos existentes no Brasil, embora teoricamente o público potencial do programa abranja o universo da categoria agricultura familiar em nível nacional.

Algumas medidas foram propostas visando alterar esse cenário de parco desempenho do financiamento da agricultura sustentável. Uma parte delas foi levada adiante com a implantação do I PLANAPO. Porém, como demonstrado no decorrer do trabalho, os resultados ficaram aquém do esperado pelas tentativas realizadas. Nesse contexto, falta ainda DOI: http://dx.doi.org/10.22295/grifos.v30i51.5548 | Edição Vol. 30, Núm. 51, 2021. 
ao Estado brasileiro colocar efetivamente em prática a ideia de sustentabilidade e adicionar a mesma ao planejamento estratégico de médio-longo prazo, na direção da construção de uma nova agricultura de base ecológica, inclusive no que diz respeito ao financiamento subsidiado da produção de alimentos saudáveis.

Para tanto, cabe ressaltar que o papel ativo dos agricultores e de suas organizações políticas se constitui em algo central no sentido de pressionar os formuladores/operadores das políticas públicas para que os mesmos avancem em relação ao fortalecimento da produção de base ecológica. Sem a formação de uma coalizão de forças sociais, que exerça pressão política perante o Estado, na atual conjuntura que se vivencia, será difícil vislumbrar qualquer mudança significativa no viés produtivista que caracteriza historicamente a política de crédito rural brasileira ou mesmo conseguir angariar outra rodada de recursos "carimbados" expressivos para o desenvolvimento rural sustentável e a agricultura ecológica.

\section{REFERÊNCIAS}

ABRAHÃO, S. S. Pronaf Agroecologia. In: WEID, J. M. von der (Ed.). Financiamento da transição agroecológica. Rio de Janeiro: ANA, 2007. p. 20-25. (Caderno do II Encontro Nacional de Agroecologia).

AHRENS, D. C. et al. A formação de profissionais holísticos e agroecológicos por meio de contribuições interdisciplinares. Revista Brasileira de Agroecologia. [S.1.], v. 4, n. 2, p. 743-746, nov. 2009.

AQUINO, J. R.; GAZOLLA, M.; SCHNEIDER, S. O financiamento público da produção agroecológica e orgânica no Brasil: inovação institucional, obstáculos e desafios. In:

SAMBUICHI, R. H. et al. (Orgs.). A Política Nacional de Agroecologia e Produção Orgânica no Brasil: uma trajetória de luta pelo desenvolvimento rural sustentável. Brasília/DF: IPEA, 2017. p. 197-227.

AQUINO, J. R.; SCHNEIDER, S. O PRONAF e o desenvolvimento rural brasileiro: avanços, contradições e desafios para o futuro. In: GRISA, C.; SCHNEIDER, S. (Orgs.). Políticas públicas de desenvolvimento rural no Brasil. Porto Alegre: Ed. da UFRGS, 2015. p. 53-81.

BACEN. Anuário estatístico do crédito rural: 1999-2012. Brasília: BACEN, 2014. Disponível em: 〈http://www.bcb.gov.br/?RELRURAL>. Acesso em: 14 jun. 2014.

BACEN. Matriz de Dados do Crédito Rural - MDCR: 2013-2015. Brasília: BACEN, 2016. Disponível em: 〈http://www.bcb.gov.br/pt-br/\#!/c/MICRRURAL/>. Acesso em: 10 out. 2016.

BUAINAIN, A. M. et al. Sete teses sobre o mundo rural brasileiro. Revista de Política Agrícola. Brasília/DF, Ano XXII, n. 2, p. 105-121, abr./maio/jun. 2013. 
BÚRIGO, F. L. Sistema Nacional de Crédito Rural: uma trajetória de privilégios, crises e oportunidades. In: VOLLES, A. (Org.). Ensaios sobre o cooperativismo solidário. Paraná: INFOCOS, 2010. p. 426-458.

CAPELlESSO, A. J.; CAZELLA, A. A.; ROVER, O. J. Ambiguidade de referenciais tecnológicos da ação pública no meio rural: agricultura familiar e limites à sustentabilidade. Desenvolvimento e Meio Ambiente. Curitiba, v. 36, p. 167-187, abr. 2016.

CARNEIRO, M. J. Política pública e agricultura familiar: uma leitura do PRONAF.

Estudos Sociedade e Agricultura. Rio de Janeiro, n. 8, p. 70-82, abr. 1997.

CIAPO. Brasil Agroecológico: Plano Nacional de Agroecologia e Produção Orgânica PLANAPO 2013-2015. Brasília/DF: MDA, 2013.

CIAPO. Plano Nacional de Agroecologia e Produção Orgânica - PLANAPO: relatório de balanço 2013-2015. Brasília, set. 2016. 92p. Disponível em:

<http://www.mda.gov.br/sitemda/sites/sitemda/files/user_arquivos_3/relatorio_de_balanco_ 2013_2015.pdf>. Acesso em: 18 jan. 2017.

DELGADO, G. C. Do capital financeiro na agricultura à economia do agronegócio: mudanças cíclicas em meio século (1965-2012). Porto Alegre: Editora da UFRGS, 2012.

DIAS, M. M. A formação do Agrônomo como agente de promoção do desenvolvimento. Revista de Extensão Rural. Ano XV, p. 53-68, jan./jun. 2008.

FECAMP. Estudos de caso em campo para avaliação dos impactos do PRONAF. Campinas, out. 2002. (Convênio PCT/IICA-FECAMP).

FRANÇA, C. G.; MARQUES, V. P. M. A.; DEL GROSSI, M. Crédito e garantia de renda para a agricultura familiar. In: BOJANIC, A. J. (Coord.). Superação da fome e da pobreza rural: iniciativas brasileiras. Brasília/DF: FAO, 2016. p. 53-79.

GASQUES, J. G. et al. Produtividade Total dos Fatores e transformações da agricultura brasileira: análise dos dados dos censos agropecuários. In: GASQUES, J. G.; VIEIRA FILHO, J. E.; NAVARRO, Z. (Orgs.). A agricultura brasileira: desempenho, desafios e perspectivas. Brasília: IPEA, 2010. p. 19-44.

GODOI, T. G.; BÚRIGO, F. L.; CAZELLA, A. A. A sustentabilidade dos financiamentos do PRONAF para a agricultura familiar. Revista Desenvolvimento e Meio Ambiente. Curitiba, v. 38, p. 637-661, ago. 2016.

GONÇALVES NETO, W. Estado e agricultura no Brasil: política agrícola e modernização econômica brasileira 1960-1980. São Paulo: HUCITEC, 1997.

GRAZIANO DA SILVA, J. A nova dinâmica da agricultura brasileira. 2. ed. Campinas/SP: UNICAMP, 1998.

GUADAGNIN, J. L. O crédito rural do PRONAF e a transição agroecológica: a visão governamental. Agriculturas. Rio de Janeiro, v. 7, n. 2, p. 18-21, jul. 2010.

IBASE. Relatório PRONAF: resultados da etapa Paraná. Rio de Janeiro: IBASE, 2006.

IBGE. Censo Agropecuário 2017: resultados definitivos. Rio de Janeiro: IBGE/SIDRA, 2019. Disponível em: <https://sidra.ibge.gov.br/pesquisa/censo-agropecuario/censoagropecuario-2017>. Acesso em: 10 maio 2020. 
KLUCK, C.; GAZOLLA, M. PRONAF e desenvolvimento rural: estudo de caso dos agricultores ecologistas de Antônio Prado/RS. In: COTRIM, D. (Org.). Desenvolvimento rural e agricultura familiar. Porto Alegre/RS: EMATER, 2014. p. 21-41.

LEITE, S. P. Crédito rural. In: CALDART, R. S. et al. (Orgs.). Dicionário da educação do campo. FIOCRUZ/Expressão Popular, 2012. p. 172-180.

MAFF. Organic Action Plan for Denmark: working together for more organics.

Denmark: MFAFD, 2015. Disponível em:

$<$ http://www.foedevarestyrelsen.dk/english/SiteCollectionDocuments/Kemi\%20og\%20foed evarekvalitet/Oekologiplan\%20Danmark_English_Print.pdf>. Acesso em: 10 nov. 2016.

MATTEI, L. A política agrária e rural no governo Temer. In: MALUF, R.; FLEXOR, G. .

(Orgs.). Questões agrárias, agrícolas e rurais: conjuntura e políticas públicas. Rio de Janeiro: Epapers Serviços Editoriais, 2017.

MATTOS, L. M. Desestruturação das políticas públicas voltadas para a agricultura familiar brasileira. In: ROSSI, P.; DWECK, E.; OLIVEIRA, A. L. M. (Orgs.). Economia para poucos: impactos sociais da austeridade e alternativas para o Brasil. São Paulo: Autonomia Literária, 2018.

MDA. PRONAF Agroecologia. Brasília/DF: SAF/MDA, 2016. (Cadernos da Agricultura Familiar - Volume 1).

MOSER, R. M. B.; GONZALEZ, L. Green microfinance: a new frontier to inclusive financial services. Revista de Administração de Empresas. São Paulo, v. 56, n. 2, p. $242-$ 250, mar./abr. 2016.

MOURA, O. N. S. Nova ruralidade no contexto da formação do profissional de agronomia. In: GOMES, A. (Org.). Da mobilização às mudanças sociais: dinâmica das novas ruralidades do Nordeste brasileiro. São Paulo/Campinas: Polis/CERES, 2006. p. 105-117.

NIERDELE, P. A. et al. A trajetória brasileira de construção de políticas públicas para a agroecologia. Redes - Revista do Desenvolvimento Regional. Santa Cruz do Sul, v. 24, n. 1, p. 270 - 291, jan./abr. 2019.

NORTH, D. C. Institutions, institutional change and economic performance. New York: Cambridge University Press, 1990.

OBSERVATÓRIO ABC. Agricultura de baixa emissão de carbono: a evolução de um novo paradigma. São Paulo: GVces/FGV, 2013. (Sumário executivo).

OBSERVATÓRIO ABC. Propostas para revisão do Plano ABC. São Paulo: GVces/FGV, 2015.

OLIVEIRA, E. C. L. O Plano Nacional de Agroecologia e Produção Orgânica: resposta a um novo paradigma de Desenvolvimento Rural para o Brasil. In: CONGRESSO

BRASILEIRO DE ECONOMIA, ADMINISTRAÇÃO E SOCIOLOGIA RURAL, 54., 2016, Maceió/AL. Anais... Maceió/AL: SOBER, 2016. 14p. (Online).

OLIVEIRA, M. A. C. et al. PRONAF Verde: política de crédito rural para o desenvolvimento da agricultura familiar sustentável. In: CONGRESSO BRASILEIRO DE ECONOMIA, ADMINISTRAÇÃO E SOCIOLOGIA RURAL, 50., 2012, Vitória/ES.

Anais... Vitória/ES: SOBER, 2012. 17p. (CD-ROM). 
PARENTE, S. Financiamento e crédito para produção e comercialização da agricultura familiar agroecológica/orgânica. In: KÜSTER, A.; MARTÍ, J. F.; FICKERT, U. (Orgs.). Agricultura familiar, agroecologia e mercado no Norte e Nordeste do Brasil. Fortaleza/CE: FKA, 2004. p. 97-109.

SABOURIN, E.; CRAVIOTTI, C.; MILHORANCE, C. The dismantling of family farming policies in Brazil and Argentina. International Review of Public Policy, (Online), v. 2, n. 1, p. 1-25, 2020.

SAMBUICHI, R. H. R.; OLIVEIRA, M. A. C. Análise das linhas de crédito do PRONAF para o desenvolvimento sustentável da agricultura familiar. Cadernos de Agroecologia. [S.1.], v. 6, n. 2, p. 1-6, dez. 2011.

SAMBUICHI, R. H. R. et al. A sustentabilidade ambiental da agropecuária brasileira: impactos, políticas públicas e desafios. Brasília: IPEA, 2012. (Texto p/ Discussão N. ${ }^{\circ}$ 1782).

SAMBUICHI, R. H. et al. (Orgs.). A Política Nacional de Agroecologia e Produção

Orgânica no Brasil: uma trajetória de luta pelo desenvolvimento rural sustentável. Brasília/DF: IPEA, 2017.

SAYAD, J. Crédito rural no Brasil: avaliação das críticas e das propostas de reforma. São Paulo: Pioneira/FIPE, 1984.

SEIBT, P. et al. Anuário brasileiro da agricultura familiar 2015. Erechim/RS: Ed. Bota Amarela, 2015.

SEN, A. Desenvolvimento como liberdade. São Paulo: Cia das Letras, 2000.

SIDERSKY, P. R. Relatório do subgrupo PRONAF. WEID, J. M. von der (Ed.).

Financiamento da transição agroecológica. Rio de Janeiro: ANA, 2007. p. 15-20.

(Caderno do II Encontro Nacional de Agroecologia).

SILVA, A. M. et al. A participação da mulher no PRONAF: uma visão geral do acesso ao programa no Brasil e regiões. In: CONGRESSO BRASILEIRO DE ECONOMIA, ADMINISTRAÇÃO E SOCIOLOGIA RURAL, 54., 2016, Maceió/AL. Anais... Maceió/AL: SOBER, 2016. 19p. (Online).

SILVEIRA, F. G. et al. Políticas públicas para o desenvolvimento rural e de combate à pobreza no campo. Brasília: IPC-IG/PNUD, 2016.

STAUB, G. A.; MELLO, R. Análise e indicações de adequações do financiamento da agricultura orgânica pelo Banco do Brasil no estado do Paraná, a partir da visão dos gerentes de financiamento rural. Revista Brasileira de Agroecologia. [S.1.], 7(2), p. 42-50, 2012.

STEIN, M. Organic Food in Public Catering new reports from Sweden and Denmark. EuroSafe News. [S.1.], v. 17, n. 2, may 2015.

TEIXEIRA, G. As dívidas e a dúvida para a agricultura familiar. [S.l.: s.n.], 2011. Disponível em: <http://www.mst.org.br/As-Dividas-e-a-Duvida-para-a-AgriculturaFamiliar>. Acesso em: 11 ago. 2011.

TEIXEIRA, G. A modernização conservadora da agricultura familiar e a agroecologia. [S.1.: s.n.], 2012. Disponível em: <http://reformaagrariaemdados.org.br/biblioteca/artigo-e- 
ensaio/moderniza\%C3\%A7\%C3\%A3o-conservadora-da-agricultura-familiar-eagroecologia>. Acesso em: 10 out. 2016.

WEID, J. M. von der. A transição agroecológica das políticas de crédito voltadas para a agricultura familiar. Agriculturas. Rio de Janeiro, v. 3, n. 1, p. 18-20, abr. 2006.

WEID, J. M. von der (Ed.). Financiamento da transição agroecológica. Rio de Janeiro: ANA, 2007. 104p. (Caderno do II Encontro Nacional de Agroecologia).

WEID, J. M. von der Agricultura familiar: sustentando o insustentável? Agriculturas. Rio de Janeiro, v. 7, n. 2, p. 4-7, jul. 2010. 